\title{
Effects of Low-Dose Solvents on the Blood of Art Restorers
}

\author{
Francesco Tomei, Tiziana Paola Baccolo, Bruno Papaleo, Marco Biagi, Stefano Signorini, \\ Benedetta Persechino and Maria Valeria Rosati
}

Department of Occupational Medicine, University of Rome "La Sapienza"

\begin{abstract}
Effects on the Blood among Art Restorers: Francesco TOMEl, et al. Department of Occupational Medicine, University of Rome "La Sapienza"-Restoration of art works is usually assessed from an artistic viewpoint, and little attention is paid to the restorers' health. There appear to be no specific published reports. Art restoration is a craftsman's job, often done by students as part of their art courses, and they are exposed to low doses of a hard-to-classify range of different substances. This study employed a protocol designed for use in the workplace to check whether art restoration work had effects on the blood of the young people doing it. We studied 65 art restorer students and teachers, most of them young, who did different types of restoration work: on stone and archaeological findings, frescoes, paintings on wood and canvas, paper and parchment, plaster, fabrics, metals, wood or painted linings. Seventy-one non-exposed workers were compared as controls. We found significant reductions in $\mathrm{RBC}, \mathrm{Hb}$ and $\mathrm{Ht}$ among exposed workers but no change in WBC. These findings suggest there may be problems in the effect on the blood of art restorers exposed to low doses of solvents. It would appear useful for these workers to undergo periodic blood screening tests, and the protocol we employed appeared suitable for identifying subjects at risk in their workplace.
\end{abstract}

(J Occup Health 1996; 38: 190-195)

Key words: Art restoration, Solvents, Multiple exposure, Low dose, Blood effects

Art restoration is usually evaluated from an artistic viewpoint, and questions of the restorers' health receive scant attention. No significant paper has been published on art restorers but even a quick glance at this sector, from another angle, immediately reveals the large number of chemicals, mainly solvents, routinely employed. This is a craftsman's

Received Dec 4, 1995 ; Accepted May 13, 1996

Correspondence to : F.Tomei, Via Monte delle Gioie 13, 00199 Rome, Italy job involving various degrees of discontinuous exposure to a variety of solvents, used in different ways for the various types and methods of restoration.

The potential toxic effects of solvents and their mixtures on the blood have been studied at high doses $^{1-4)}$ and even at low doses ${ }^{58}$. Studies on other categories of workers found a correlation between exposure to solvents and changes in the blood. $\phi$ rbaek et al. ${ }^{1)}$ studied workers in the paint-making industry exposed to organic solvents: they showed a general tendency to a low RBC count. In a group of painters and mechanics exposed to low doses of solvents, Beving et al. ${ }^{5)}$ found a reduction in the RBC count and an increase in the mean red cell volume but no real differences between exposed subjects and controls in the platelet count or volume.

Considering that young people may be more susceptible to effects on the blood, and therefore should be safeguarded more carefully, we studied art students and teachers, most of them young, in an art restoration institution. We therefore used an easy-to-administer protocol designed for use in the workplace to assess whether art restoration could lead to effects on the blood independently of effects on the liver of young people doing this work.

\section{Materials and Methods}

We studied 65 art restorers, students and teachers of both sexes (mean age $29.1 \mathrm{yr}$, SD 8.3 , range 20 58 ), with $3.0 \pm 1.5$ years of work experience. There were 50 women, (mean age $26.8 \pm 5.0 \mathrm{yr}$ range $20-$ 42 ) and 15 men (mean age $36.9 \pm 11.9 \mathrm{yr}$, range 24 -58). They alternate theoretical lessons during the week with practical sessions in the workshop, taking part in all types of restoration work: on stone and archaeological findings, frescoes, paintings on wood and canvas, paper and parchment, plaster, fabrics, metals, wood or painted linings.

The main solvents used in these jobs are ethanol, amyl-acetate, acetone, ammonia, hydrogen peroxide, butylamine, diacetone alcohol, dimethyl-formamide, 
oil and spirits of turpentine, petroleum, paraffin ethers, toluol, xylol, trichloroethane, trichloroethylene, polyvinyl acetate, aniline carbon tetrachloride, formaldehyde, phenols, methanol, nitrodiluents, mixtures of benzenic hydrocarbons, ethylene-chloride, methylchloride and methyl bromide.

In the presence of a physician, a targeted clinical history questionnaire was completed and each subject underwent a general clinical examination. The questionnaire was also focused on identifying the confounding factors such as pathologies involving changes in the blood, alcohol consumption, smoking habit, hemotoxic and hepatotoxic drugs assumption and history of liver diseases. The following laboratory tests were done: white blood cell count (WBC) with differential fromula, red blood cells count (RBC), platelets count (PLT), hemoglobin concentration $(\mathrm{Hb})$, hematocrit (Hct). To assess the general health of the subjects, in consideration of the fact that it has been suggested that low dose exposure to solvents may affect the liver ${ }^{9-13)}$ the following hepatic tests were done: total and conjugated bilirubin, serum aspartate aminotransferase (AST), serum alanine aminotransferase (ALT), cholinesterase, $\gamma$-glutamyltransferase $(\gamma$-GT $)$ and alkaline phosphatase (AP). Reference values for all the tests were those commonly used by our laboratory: WBC $4,800-10,800 / \mathrm{mm}^{3}$; RBC males $470-610 \times 10^{4}$ $/ \mathrm{mm}^{3}$, females $420-540 \times 10^{4} / \mathrm{mm}^{3}$; PLT $130-400 \times$ $10^{3} / \mathrm{mm}^{3} ; \mathrm{Hb}$ males $14-18 \mathrm{~g} / \mathrm{d} l$, females $12-16 \mathrm{~g} / \mathrm{d} l$, Hct males $42-52 \%$, females $37-47 \%$; total bilirubin $<1 \mathrm{mg} / \mathrm{d} l$; conjugated bilirubin $<0.25 \mathrm{mg} / \mathrm{d} l$; AST $<46$ IU; ALT $<49$ IU; $\gamma$-GT males $<55$ IU, females $<50$ IU; AP $<290$ IU.

We assessed the biological indicators for certain solvents, for which reliable, routinely employed methods are available, to confirm the occupational and non occupational exposure to low doses. In 24 $\mathrm{h}$ urine of the exposed subjects the following indicators were assayed: hippuric acid (exposure to toluol), phenol (exposure to benzol and phenols), trichloroacetic acid [exposure to halogenated aliphatic hydrocarbons (trichloroethylene, trichloroethane)] and vanylmandelic acid (exposure to amyl acetate). The colorimetric-spectrophotometric method described by Tomokuni et al. ${ }^{14)}$ was used to determinate urinary hippuric acid; the urinary trichloroacetic acid concentration was measured following the colorimetric-spectrophotometric method of Grisler et al. ${ }^{15)}$; vanylmandelic acid was measured following the chromatographic and colorimetric-spectrophotometric method described by Wybenga et $a l^{16)}$ and urinary phenol was detected by spectrophotometry following the method described by Yamuguchi et al. ${ }^{17)}$.
We selected a control group of 71 workers in different jobs, occupationally and non-occupationally unexposed to the risk of contact with substances likely to affect the blood or liver (in particular solvents) and homogeneous with the exposed group as regards age, working life and confounding factors (mean age $31.0 \pm 6.9 \mathrm{yr}$, range 21-50); 40 were women (mean age 28.2 $\pm 5.2 \mathrm{yr}$, range 21-37) and 31 men (mean age $34.5 \pm 7.4 \mathrm{yr}$, range $23-50$ ). All the control subjects underwent the same laboratory tests as the exposed subjects, but biological monitoring was not performed because the controls inclusion criteria excluded any exposure to solvent.

The statistical analysis included calculation of the mean, standard deviation and $95 \%$ confidence interval; differences between the group means were evaluated by Student's t-test. Frequencies in the groups were compared with the chi-squared test with Yates' continuity correction creating contingency tables. The dose-response relationship was evaluated by regression analysis considering hippuric acid as an indicator of the internal dose and the hemathologic indices as indicators of the effect. A significance level of $p<0.05$ was used. The statistical analysis was performed by using a SOLO ${ }^{\mathrm{TM}}$ statistical package (BMDP Statistical Software, Inc).

\section{Results}

The results obtained from the questionnaire answers findings did not differentiate between the exposed group and the controls.

RBC were below the lower reference limit value (threshold) in $50.7 \%$ of the exposed workers (controls $7 \% ; \mathrm{p}<0.001)$; Hb was low in $21.5 \%$ of exposed workers, (controls $7 \% ; \mathrm{p}<0.05$ ) ; Hct was low in $44.6 \%$ of cases and $8.4 \%$ of controls $(p<$ $0.001)$. WBC were the same in both groups and no subjects in the exposed or control group had a PLT below the threshold (Table 1).

Comparing the men separately, $46.6 \%$ of the exposed workers had a RBC below the lower limit of normal (controls $6.4 \% ; \mathrm{p}<0.005$ ); $\mathrm{Hb}$ was low in $26.6 \%$ of cases, compared to $6.4 \%$ of controls (not

Table 1. Prevalence of tests below the threshold (lower reference limit value) in the two groups of subjects

\begin{tabular}{lcl}
\hline & $\begin{array}{c}\text { Exposed } \\
65\end{array}$ & $\begin{array}{c}\text { Controls } \\
71\end{array}$ \\
\hline RBC & $33(50.7 \%)^{*}$ & $5(7.0 \%)$ \\
$\mathrm{Hb}$ & $14(21.5 \%)^{* *}$ & $5(7.0 \%)$ \\
$\mathrm{Hct}$ & $29(44.6 \%)^{*}$ & $6(8.4 \%)$ \\
PLT & 0 & 0 \\
WBC & $10(15.4 \%)$ & $7(9.8 \%)$ \\
\hline
\end{tabular}

"p $<0.001, " \mathrm{p}<<0.05$. 
significant); Hct was low in $46.6 \%$ of cases (controls $6.4 \% ; p<0.005$ ) and WBC were low in $20 \%$ of the exposed workers, as against $16.1 \%$ of controls (not significant) (Fig.1); no subjects in the exposed or control group had a PLT below the threshold. Table 2 shows the mean values and 95\% confidence interval of the blood indices: among the exposed males, mean RBC counts and Hct were significantly lower than controls $(p<0.001)$, as were PLTs $(p<0.05)$ but the differences in mean WBC and $\mathrm{Hb}$ were not significant.

Taking the women separately, $52 \%$ of the exposed workers had an RBC below the lower limit of normal (controls $7.5 \% ; \mathrm{p}<0.001$ ); $\mathrm{Hb}$ was low in $20 \%$ of cases, compared to $7.5 \%$ of controls (not significant); Het was low in $44 \%$ of cases (controls $10 \% ; \mathrm{p}<0.001)$ and WBCs were low in $14 \%$ of the exposed workers, as against $5 \%$ of controls (not significant); no subjects in the exposed or control group had a PLT below the threshold. Table 2 shows the mean values and $95 \%$ confidence interval of the blood indices: among exposed females, mean $\mathrm{RBC}, \mathrm{Hb}$ and $\mathrm{Hct}$ were all significantly lower than controls $(\mathrm{p}<0.001)$ while WBC and PLT were virtually the same.

In $20 \%$ of workers only one variable was below the lower limit of normal ( 3 males, 20\% and 10 females, $20 \%$ ), compared with $14.1 \%$ of controls ( 6 males, $19.3 \%$ and 4 females, $10 \%$ ); $21.5 \%$ had two variables below normal (2 males, $13.3 \%$, and 12 females, $24 \%$ ), compared with $2.8 \%$ of controls ( 1 male, $3.2 \%$, and 1 female, $2.5 \%)(\mathrm{p}<0.005)$. Three variables were low in $18.4 \%$ of the exposed workers ( 2 males, $13.3 \%$, and 10 females, $20 \%)$ and four were low in $3 \%$ ( 2 males, $13.3 \%$, no females), but in none of the controls.

As far as liver function tests were concerned we found normal findings both in exposed and control

Table 2. RBC, WBC, PLTS, Het, Hb values in male and female exposed subjects and controls

\begin{tabular}{|c|c|c|c|c|c|}
\hline \multicolumn{6}{|c|}{ Males } \\
\hline Group & $\begin{array}{c}\text { RBC } \\
\text { number } / \mathrm{mm}^{3}\end{array}$ & $\begin{array}{c}\text { WBC } \\
\text { number } / \mathrm{mm}^{3}\end{array}$ & $\begin{array}{c}\text { PLT } \\
\text { number } / \mathrm{mm}^{3}\end{array}$ & $\begin{array}{l}\mathrm{Hb} \\
\mathrm{g} / \mathrm{d} l\end{array}$ & $\begin{array}{c}\text { Het } \\
\%\end{array}$ \\
\hline Mean & $453 \times 10^{4}$ & 5893.3 & $26 \times 10^{4}$ & 14.4 & 40.8 \\
\hline Exposed SD & $653 \times 10^{4}$ & 1627.2 & $1.7 \times 10^{4}$ & 1.1 & 3.4 \\
\hline $\mathrm{n}=15 \quad 95 \%$ & $416.8 \times 10^{4}$ & 4992.4 & $25.1 \times 10^{4}$ & 13.8 & 38.9 \\
\hline c. $\mathrm{i}$. & $489.1 \times 10^{4}$ & 6794.2 & $26.9 \times 10^{4}$ & 15.1 & 42.7 \\
\hline Minimum & $290 \times 10^{4}$ & 2200 & $23 \times 10^{4}$ & 11.8 & 32 \\
\hline Maximum & $520 \times 10^{4}$ & 8200 & $28 \times 10^{4}$ & 16.0 & 45 \\
\hline Mean & $509.1 \times 10^{4}$ & 6897.4 & $22 \times 10^{4}$ & 14.4 & 45.1 \\
\hline Controls SD & $31.0 \times 10^{4}$ & 2019.9 & $5.8 \times 10^{4}$ & 1.1 & 2.7 \\
\hline $\mathrm{n}=31 \quad 95 \%$ & $497.8 \times 10^{4}$ & 6156.5 & $19.9 \times 10^{4}$ & 13.8 & 44.1 \\
\hline c. i. & $520.5 \times 10^{4}$ & 7638.3 & $24.1 \times 10^{4}$ & 15.1 & 46.1 \\
\hline Minimum & $430 \times 10^{4}$ & 3670 & $15.3 \times 10^{4}$ & 13.2 & 39 \\
\hline Maximum & $587 \times 10^{4}$ & 11,000 & $35.2 \times 10^{4}$ & 18.0 & 53 \\
\hline t-test & $<0.001$ & ns & $<0.05$ & ns & $<0.001$ \\
\hline \multicolumn{6}{|c|}{ Females } \\
\hline Group & $\underset{\text { number } / \mathrm{mm}^{3}}{\mathrm{RBC}}$ & $\begin{array}{c}\text { WBC } \\
\text { number } / \mathrm{mm}^{3}\end{array}$ & $\underset{\text { number } / \mathrm{mm}^{3}}{\text { PLT }}$ & $\begin{array}{c}\mathrm{Hb} \\
\mathrm{g} / \mathrm{d} l\end{array}$ & $\begin{array}{c}\mathrm{Hct} \\
\%\end{array}$ \\
\hline Mean & $416.0 \times 10^{4}$ & 6050.0 & $26.1 \times 10^{4}$ & 12.8 & 36.9 \\
\hline Exposed SD & $30.0 \times 10^{4}$ & 1128.4 & $4.6 \times 10^{4}$ & 0.9 & 2.3 \\
\hline $\mathrm{n}=50 \quad 95 \%$ & $407.4 \times 10^{4}$ & 5737.2 & $24.8 \times 10^{4}$ & 12.5 & 36.3 \\
\hline c. i. & $424.5 \times 10^{4}$ & 6378.7 & $27.4 \times 10^{4}$ & 13.1 & 37.6 \\
\hline Minimum & $360 \times 10^{4}$ & 4,000 & $16.5 \times 10^{4}$ & 10.4 & 32 \\
\hline Maximum & $490 \times 10^{4}$ & 8,400 & $50 \times 10^{4}$ & 14.8 & 43 \\
\hline Mean & $488.3 \times 10^{4}$ & 6407.7 & $24.6 \times 10^{4}$ & 13.7 & 41.2 \\
\hline Controls SD & $58.3 \times 10^{4}$ & 1392.1 & $5.1 \times 10^{4}$ & 1.3 & 3.7 \\
\hline$n=40 \quad 95 \%$ & $469.6 \times 10^{4}$ & 5962.5 & $23 \times 10^{4}$ & 13.3 & 40.1 \\
\hline c. i. & $506.9 \times 10^{4}$ & 6852.9 & $26.3 \times 10^{4}$ & 14.1 & 42.4 \\
\hline Minimum & $378 \times 10^{4}$ & 2,600 & $15.8 \times 10^{4}$ & 11 & 33 \\
\hline Maximum & $630 \times 10^{4}$ & 9,020 & $38 \times 10^{4}$ & 16 & 48 \\
\hline t-test & $<0.001$ & ns & ns & $<0,001$ & $<0.001$ \\
\hline
\end{tabular}


Table 3. Urinary biological indicators in the exposed subjects

\begin{tabular}{cc}
\hline & $\begin{array}{c}\text { Exposed } \\
65\end{array}$ \\
& $\begin{array}{c}\text { mean } \pm \mathrm{SD} \text { (range) } \\
(\text { reference values) }\end{array}$ \\
\hline Phenol & $21.46 \pm 7.94(3-43)$ \\
$\mathrm{mg} / l$ & $(<50 \mathrm{mg} / 24 \mathrm{~h})$ \\
$\mathrm{Hippuric}$ acid & $619.97 \pm 273.59(208-1,480)$ \\
$\mathrm{mg} / l$ & $(200-1,660 \mathrm{mg} / 24 \mathrm{~h})$ \\
Trichloroacetic acid & $0.95 \pm 1.07(0-5.50)$ \\
$\mathrm{mg} / l$ & $(<5.5 \mathrm{mg} / 24 \mathrm{~h})$ \\
Vanylmandelic acid & $5.34 \pm 2.66(0-11)$ \\
$\mathrm{mg} / l$ & $(<10 \mathrm{mg} / 24 \mathrm{~h})$ \\
\hline
\end{tabular}

range $=$ minimum- maximum interval.

subjects. Biological indicators showed no values outside the normal range. The evaluation of the dose-response relationship did not show any significant result (Table 3).

\section{Discussion}

As technical methods for preventing exposure in the work place have improved, contact with frankly toxic high concentrations of xenobiotics hardly ever occurs any longer, except for accidents. Workers are mostly exposed to low doses, generally within the limits set for TLVs, especially in the service sectors. There are numerous definitions of a low dose but one of the most widely accepted, by Barnes ${ }^{18)}$, states virtually that a low dose is defined as such if it is one or two orders of magnitude lower than the dose of a certain substance that produces a clear toxic effect. Exposure to low doses may be toxic not only for the very small numbers of workers who show individual susceptibility, but possibly also for the working population as a whole. There are several grounds for suggesting this: the growing number of occupational and extra-occupational xenobiotics to which workers are exposed may give rise to interactions ("multideterminism") ; exposure during each day and working week may be discontinuous, with the possibility of exposure to high doses; the conviction is growing in the scientific community that TLVs and EBI values need to be reconsidered for various reasons (genetic variability, stochastic effects and "multideterminism").

The art restorer's job we investigated offers a good model of these problems. Restorers are in fact usually exposed to low doses on a discontinuous, unpredictable basis, or to occasional, equally unpredictable high doses. In these circumstances it is logical to suspect that some of the substances involved may have pathogenic effects. This study found that art restorers did in fact have changes in their blood values compared to controls. The values were just below normal for men, and only slightly higher for the women. The difference between the sexes was limited and we cannot say whether it indicates that women are more susceptible. The fact that the abnormal values were only slightly outside the normal range, and deviate very little from the controls, raises several questions: Do these changes have any real clinical significance? Do doses below the current TLVs only affect certain susceptible subjects or should they be considered an expression of risk for the whole exposed population? Can such effects really be detected with non-specific health survey tools such as basic blood tests? In our opinion the clinical significance of these changes for the exposed workers is uncertain and did not induce us to take the dramatic decision of removing the affected art restorers from their work. But our data seem to mean that doses below the TLVs may represent a risk factor not only for individual susceptible subjects but for the whole population. The effects on the blood of the exposure to low doses of solvents may be better detected by a health surveillance protocol, easy to administer in the workplace, than by exceedingly specific and expensive biochemical tests, not feasible in the workplace and not suitable for low dose exposure to different xenobiotics.

The modifications in the blood we observed appear to be related to exposure to the solvents used in restoration, since there was no appreciable difference between exposed workers and controls as regards confounding factors, and since the sample did not include any subjects with pathologies involving changes in the blood.

Our data showed a significant RBC count decrease without any WBC alteration. Toxic blood changes may usually be linked either to a direct effect of xenobiotics on bone marrow or to a direct effect on circulating blood cells : the lack of hemolysi's leads us to hypothesize that the toxic effect is related to a bone marrow inhibition and not to a direct hemolytic effect such as described for aniline ${ }^{19)}$.

Published findings on the effects of solvents on the blood do not allow us to attribute greater importance in determining blood effects to one of the solvents used in art restoring, though a lower RBC count was shown in workers (paint-making industries, painters and mechanics) exposed to low doses of solvent mixtures) ${ }^{1,5}$.

The modification of the blood indices we found cannot be ascribed with certainty to one of the xenobiotics to which art restorers were exposed and although the hematologic effects observed are not typ- 
ical of early changes due to benzene exposure we have to point out that benzenic impurities-usually present in toluol, xylol and nitro diluents-may exert a toxic effect on blood cells. Benzene is a well established hematotoxic agent that affects both developing blood cells and bone marrow stromal cells. Hematologic findings following occupational exposure include anemia, aplastic anemia, leukopenia, rarely leukocytosis, blood dyscrasias with hemolytic effects, pancytopenia etc. ${ }^{20)}$ Its effects usually occur in three stages ranging from a slight decrease in the number of circulating blood cells to progressive bone marrow aplasia ${ }^{20)}$.

We have to point out that the workers we studied are also exposed to phenols: recently $\mathrm{Hsieh}$ et al. ${ }^{20)}$ showed in mice exposed to phenol a depression of the $\mathrm{RBC}$ count in the absence of any change in the WBC count. Phenol, a primary metabolite of benzene, is more toxic to bone marrow than benzene itself: bone marrow shows high levels of peroxidase for which phenol is a known substrate (probable products are hydroquinone and catechol). Phenol can be activated by co-oxidation with prostaglandins to more reactive substances such as semiquinone and such a mechanism may be responsible for the hematotoxicity of phenol.

As far as the lack of leukopenia is concerned we have to report the study of Ikeda et al. ${ }^{22)}$ which showed that the simultaneous exposure to toluene in rats protects against benzene induced leukopenia. Such an effect has not been definitely proved in humans but it allows us to hypothesize that the multiple exposure to several solvents may lead to not easily understandable metabolic interactions on bone marrow ${ }^{23}$.

We found no hepatic modifications, not only because of the low doses but also because of the youth and short working life of the subjects, since it would appear that longer exposure to low doses is necessary to produce liver effects.

During such work as art restoration, involving low doses of solvents, environmental or biological monitoring would appear to be of little use. The difficulty of identifying and quantifying the numerous substances present, the low doses, varying with time, the complexity and high cost of analyzing them all makes it impossible to propose any correct form of environmental or biological monitoring. It does, however, confirm the importance of primary prevention in these cases, focusing on the installation of appropriate equipment and even on nonspecific health surveillance.

Biological monitoring findings were normal despite the changes in blood we found confirming that biological monitoring, like environmental monitoring, is impracticable. It may simply be useful to organize health surveillance for workers exposed to low doses ${ }^{24,25)}$.

It would appear, however, that before a population exposed to low doses is scheduled for screening, the occupational physician should make a preliminary assessment of the risk, to identify the lowdose exposure that has no effects on the population and/or on individuals and causes no effects in exposed subjects.

The present findings suggest it may be useful for young art restorers to undergo periodic blood screening tests. The protocol employed appears useful for identifying subjects at risk and establishes how often tests need to be made, depending on the extent to which the variables investigated are altered.

\section{References}

1) фrbaek P, Haeger-Aronsen B, Hjortsberg U, Welinder $\mathbf{H}$. Are the results of clinical chemistry on blood samples from workers exposed to organic solvents of any diagnostic value? In: Fournier E, Efthymiou ML, eds. Toxicovigilance industrielle, Metaux et solvants. Actes du X Congrès du Medichem. Paris: Masson, 1982: 157-163.

2) Pedersen LM. Biological studies in human exposure to and poisoning with organic solvents. With special reference to kinetics, haematology and serum chemistry. Pharmacol Toxicol 1987; 61(suppl 3): 1-38.

3) Smith RP. Toxic responses of the blood. In: Amdur MO, Doull J, Klaassen CD, eds. Casarett and Doull's Toxicology. The basic science of Poison. New York: Pergamon Press, 1991: 257-281.

4) Uchida $Y$, Nakatsuka $H$, Ukai $H$, et al. Symptoms and signs in workers exposed predominantly to $\mathrm{xy}$ lenes. Int Arch Occup Environ Health 1993; 64 : 597-605.

5) Beving H, Tornling G, Olsson P. Increased erythrocyte volume in car repair painters and car mechanics. Br J Ind Med 1991; 48: 499-501.

6) Hagmar L, Högstedt B, Welinder H, Karlsson A, Rassner F. Cytogenic and hematological effects in plastic workers exposed to styrene. Scand J Work Environ Health $1989 ; 15$ : 136-141.

7) Larese F, Fiorito A, De Zotti R. The possible haematological effects of glycol monomethyl ether in a frame factory. Br J Ind Med 1992; 49: 131-133.

8) Ulfvarson U, Alexandersson $R$, Dahlquist $M$, Ekholm U, Bergström B, Scullman J. Temporary health effects from exposure to water-borne paints. Scand J Work Environ Health 1992; 18: 376-387.

9) Edling C, Ekberg K, Ahlborg G, et al. Long term follow up of workers exposed to solvents. $\mathrm{Br} \mathrm{J}$ Ind Med 1990; 47: 75-82.

10) Edling, C. Interaction between drugs and solvents as a cause of fatty change in the liver? $\mathrm{Br} \mathrm{J}$ Ind Med $1982 ; 39: 198-199$. 
11) фrbaek P, Risberg J, Rosén I, et al. Effects of long term exposure to solvents in the paint industry. Scand J Work Environ Health 1985; 11 (suppl. 2) : 128.

12) Rees D, Soderlund N, Cronjie R, Song E, Kielkowski $\mathrm{D}$, Myers J. Solvent exposure, alcohol consumption and liver injury in workers manufacturing paint. Scand J Work Environ Health 1993; 19: 236-244.

13) Sotaniemi EA, Sutinen S, Arranto AJ, Pelkonen R. Liver injury in subjects occupationally exposed to chemicals in low doses. Acta Med Scand 1982; 212 : 207-215.

14) Tomokuni K, Ogata M. Direct colorimetric determination of hippuric acid in urine. Clin Chem 1972; 18 : $349-351$.

15) Grisler R, Griffini AM. Semimicrometrico rapido e screening test per la determinazione dell'acido tricloroacetico nelle orine. Med Lavoro 1970; 61: 509512.

16) Wybenga D, Pileggi VJ. Quantitative determination of 3-methoxy-4-hydroxy-mandelic acid (VMA) in urine. Clin Chim Acta 1966; 16:147-154.

17) Yamaguchi $Y$, Hayashi C. Determination of urinary total phenolic compounds with use of 4 Aminoantipyrine: suggested screening test for hypertiroidism and for catecholanine-producing tumor. Clin Chem 1977; $23:$ 2151-2154.

18) Barnes JM. Assessing hazards from prolonged and repeated exposure to low doses of toxic substances.
Br Med Bull 1975; $31:$ 142-145.

19) Benya TJ, Cornish HH. Aromatic nitro and amino compounds. In: Clayton GD, Clayton FE, eds. Patty's Industrial Hygiene and Toxicology. New York: Wiley, 1991: 947-1086.

20) Cavender F. Aromatic hydrocarbons. In: Clayton GD, Clayton FE eds. Pattty's Industrial Hygiene and Toxicology. New York: Wiley, 1991: 13011442 .

21) Hsieh GC, Sharma RP, Parker RDR, Coulonbe RA Jr. Immunological and neurobiochemical alterations induced by repeated oral exposure of phenol in mice. Europ J Pharmacol 1992; 228: 107-114.

22) Ikeda M, Hirayama T. Alleviation of benzene leukopenia in rats simultaneously exposed to toluene. Arch Hig Toksikol 1979; 30 (suppl) : 477-481.

23) Tardif R, Goyal R, Brodeur J. Assessment of occupational health risk from multiple exposure: review of industrial solvent interaction and implication for biological monitoring of exposure. Toxicol Ind Health $1992 ; 8: 37-52$.

24) Tomei F. Sul Comportamento della crasi ematica periferica in lavoratori addetti alla produzione di fibre poliacriliche. Recentia Medica 1983; 22: 133138.

25) Tomei F, Iavicoli S, Iavicoli A, Papaleo B, Baccolo TP. Liver damage in pharmaceutical industry workers. Arch Environ Health 1995; 50: 293-297. 